\title{
Strategies to Prevent Postoperative Nausea and Vomiting
}

\author{
Onur KOYUNCU,' (D) Senem URFALI,' (D) Sedat HAKIMOĞLU,' (D) A. Muhittin TAŞDOĞAN²
}

'Department of Anesthesiology and Reanimation, Hatay Mustafa Kemal University, Hatay-Turkey

2Department of Anesthesiology and Reanimation, Hasan Kalyoncu University, Gaziantep-Turkey

\begin{abstract}
SUMMARY
Nausea and vomiting seen within the post-operative recovery room or 24 hours following the operation remain one of the most common complications in the postoperative period. Nausea and vomiting decrease the patient's postoperative satisfaction, which may lead to complications, such as aspiration of gastric contents, dehydration, electrolyte imbalance, hemorrhage, it may also bring about economic losses, prolongs recovery time and length of hospital stay. Therefore, in the preoperative process, it is very important to investigate the risks correctly for each patient concerning postoperative nausea and vomiting and to identify and apply risk-reducing pharmacological and non-pharmacological treatment methods. In this review, the importance of postoperative nausea and vomiting, risk factors, strategies to reduce risks and the treatment algorithm used in prophylaxis are presented.

Keywords: Postoperative nausea-vomiting; postoperative nausea-vomiting risk factors; postoperative nausea-vomiting prevention; postoperative nausea-vomiting treatment algorithm.

Copyright $\odot$ 2020, Turkish Society for Radiation Oncology
\end{abstract}

\section{Introduction}

\section{Definition of PONV}

Postoperative nausea and vomiting (PONV) is an issue that has achieved high attention in the 1990s and never lost its popularity concerning anesthesia. Briefly, PONV is the feeling of nausea, vomiting and retching within 24 hours after the operation or in the recovery room.

\section{Significance of PONV}

A study about the importance of PONV, patients were asked to write 10 outcomes, starting with the most unwanted outcome in the postoperative period. At the end of the study, vomiting was taken the first order, and incision pain was the third. In other words, vomiting was the most undesirable complication and was even more important than incisional pain for patients.[1] In another study, patients were asked how much they would pay for an antiemetic if it were guaranteed that they would not have PONV experience. The patients agreed to pay an average of $\$ 56(26-97)$. In the same study, when the patients were asked how much they would pay to avoid PONV, they agreed to pay $\$ 73(44-$ 110).[2] In another study, families whose children had surgery in the last two years were selected, and their parents were asked how much they would pay to prevent their children from having PONV. The families agreed to pay around $\$ 80$. The families also mentioned that they were very worried about PONV.[3] In a study on the cost of PONV, it was mentioned that each vomiting attack caused the patient to leave the recovery room 24 minutes later. In addition, the total cost of staff, support equipment, medication for each patient with a PONV attack was approximately \$15.[4] As a result, the importance of PONV is:

- A serious stress factor for patients and parents

- Cause of morbidity 
(Aspiration, suture opening, esophageal rupture, electrolyte imbalance, dehydration)

- Prolongation of recovery

- Cause of admission to the hospital

When all these results are considered, it is seen that PONV increases hospital costs significantly.

\section{Incidence of PONV}

There are serious complications that are very important in anesthesia practice but have a low incidence. Malignant hyperthermia is a good example. It is very important when it occurs; however, its incidence is around $1 / 15000$, whereas PONV is both important and its incidence is high. In the postoperative stage, the general vomiting incidence is $30 \%$, general nausea incidence is $50 \%$. Moreover, PONV incidence increases up to $70-80 \%$ in patients with a high risk of nausea-vomiting.[5]

\section{PONV Risk Factors \\ Adults}

Upon the rise of interest in PONV and the increase in the publications, it has been decided to bring experts throughout the world and to publish a guideline in 2003. It was reported that giving prophylaxis to each patient against the risk of PONV increases the costs and exposed patients to the side effects of the medications. It was mentioned that prophylaxis should only be administered to patients with medium and high risk for this reason.[6]

The risk factors related to PONV were published in the 2003, 2007 and 2014 guidelines with certain differences. The risk factors specific to patients in the 2003 guideline were belonging to the female gender, non-smoking status and the history of PONV or motion sickness. The modifiable or anesthesia-related risk factors are the use of volatile anesthetics, nitrous oxide, intraoperative and postoperative opioids. As for surgical risk factors, the duration of surgery is important. Each 30-minute extension in the duration of surgery increases basal risk around 60\%. In addition, surgical types are also important (laparoscopy, earnose-throat, neurosurgery, breast, strabismus, laparotomy, plastic surgery).[6] There is no much difference between the 2003 and 2007 guidelines, only the type of operation has been increased (laparoscopy, laparotomy, breast, strabismus, plastic surgery, maxillofacial, gynecological, abdominal, neurologic, ophthalmologic, urologic).[7] In the guideline of 2014, being under the age of 50 was exactly added as a risk factor. When all surgery groups were analyzed, cholecystectomy, gynecological and laparoscopic surgeries carried more risk. It was emphasized that intraoperative opioids posed a weak risk and no difference between opioid types.[8]

\section{Children}

Unlike adults in children, all data were collected on vomiting in the literature because it is not quite possible to evaluate nausea objectively. PONV is not frequently seen in children under the age of two. In children over three years of age, the incidence of vomiting is twice that of adults and around $40 \%$. When the three consecutive guidelines are considered concerning risk factors, a big difference is not seen in children.

\section{Simplified Risk Scores for Predicting PONV}

In 1999, Apfel et al. determined simplified risk scoring for adults. According to this scoring, there are four independent predictors as follows:

- Female gender

- Non-smoking status

- History of nausea-vomiting or motion sickness

- Postoperative opioid consumption

The risk factors are summed and an estimated PONV percentage is determined. For instance, if there is $0,1,2,3,4$ risk factors, PONV risk respectively about $10 \%, 20 \%, 40 \%, 60 \%$ and $80 \%$.[5]

Similar to the adult PONV scoring, Eberhart et al. have defined a simple risk score for PONV purposes in pediatrics. There are four independent predictors in this scoring system:

- Duration of surgery $\geq 30$ minutes

- Age $\geq 3$

- Strabismus surgery

- History of postoperative vomiting in the patient, the parents of the patient and the twin of the patient

In the same manner, the risk factors are summed and a postoperative vomiting (POV) percentage is determined. For instance, if there is $0,1,2,3,4$ risk factors, the risk of POV $10 \%, 10 \%, 30 \%, 50 \%$ and $70 \%$. [9]

Due to the increasing number of outpatient surgeries nowadays, a nausea-vomiting scoring was created for the post-discharge period. Five independent predictors were determined in this scoring system as follows:

- Female gender

- PONV history

- Being under the age of 50

- Use of opioids in the recovery room

- Nausea in the recovery room

According to this scoring system, if there is $0,1,2$, 3, 4, 5 risk factors, the risk of post-discharge nausea and vomiting (PDNV) 10\%, 20\%, 30\%, 50\%, 60\% and 89\%.[10] 


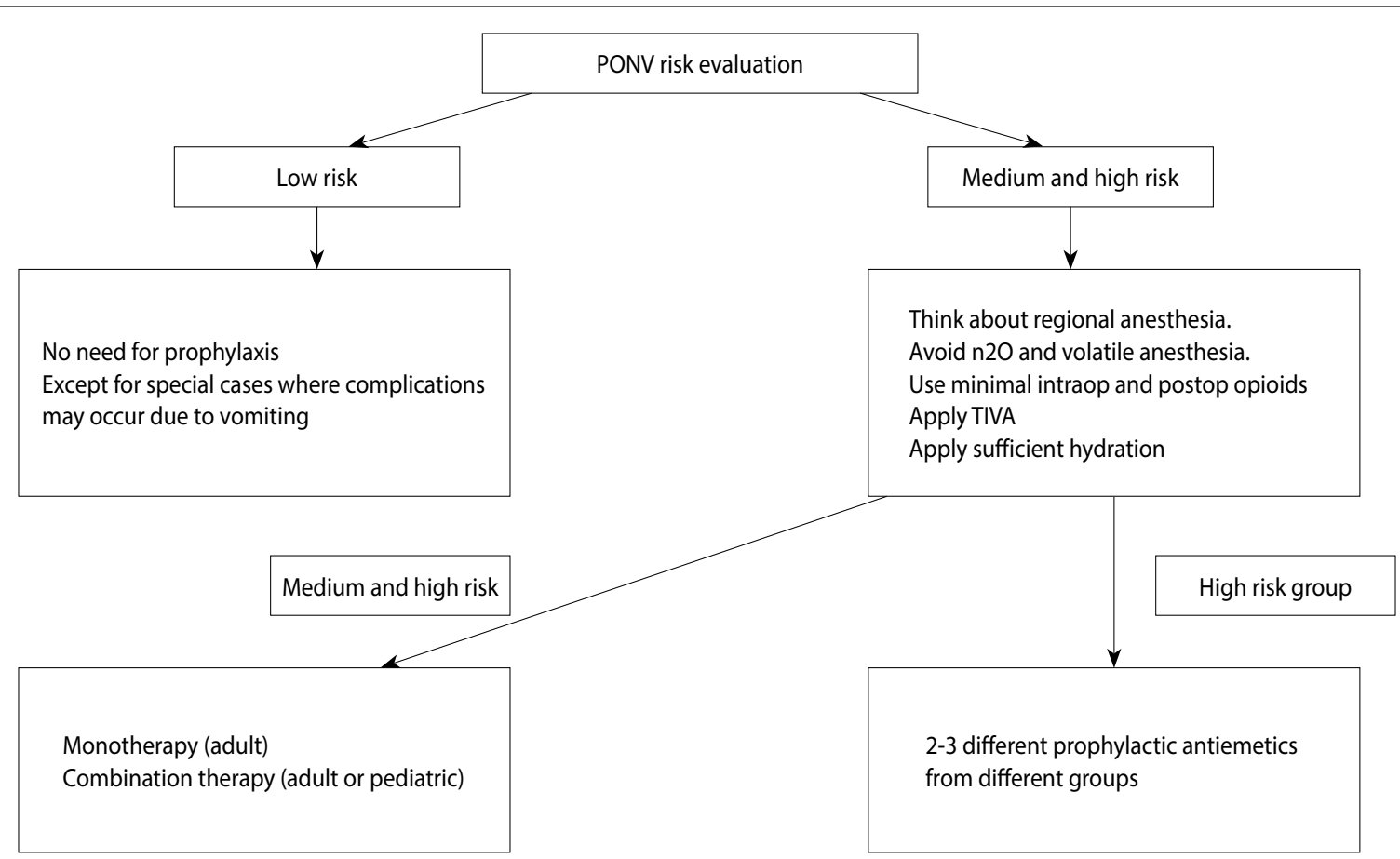

Fig. 1. Postoperative nausea and vomiting (PONV) prophylaxis algorithm.

\section{The Strategies which Reduce Basal Risks}

In the prevention of PONV, pharmacological treatments are not sufficient enough. Therefore, strategies that reduce basal risks were included in all three of the guidelines. In the 2003 guideline, it was stated that regional anesthesia reduces PONV 11 times compared to general anesthesia. It was reported that the use of propofol in induction and maintenance reduces PONV in an effective manner in particular in the first six hours. Although it was changed in the other two guidelines, perioperative support oxygen (80\%) reduces PONV by $50 \%$. While hydration reduces PONV, nitrous oxide, volatile anesthetics, intraoperative/postoperative opioids and high dosage neostigmine $(\geq 2.5 \mathrm{mg})$ increases PONV. Similar to multimodal analgesia, a multimodal approach is superior to monotherapy in the prevention of PONV. [6] The support oxygen treatment found in the 2003 guideline did not exist in the 2007 guideline. The reducing effect of propofol was indicated in the 2007 guideline as well. Meanwhile, two published meta-analyzes indicate that the absence of nitrous oxide reduces PONV. It was reported that volatile anesthetics increased PONV, especially in the first two hours and not effective in the remaining 22 hours. In addition, non-opioid analgesics and ketamine reduce PONV through a mechanism to reduce opioid use.[7]
In 2004, a publication in NEJM (IMPACT) presented important findings of the issue. Five thousand one hundred ninety-nine patients were applied to six different treatment strategies. In patients who used volatile anesthetics or nitrous oxide, the PONV incidence was indicated as $59 \%$. It was determined that the use of propofol reduces the risk of PONV by $19 \%$, non-use of nitrous oxide by $12 \%$ and application of total intravenous anesthesia (TIVA) by $25 \%$. In the same study, it is stated that the use of ondansetron $4 \mathrm{mg}$, droperidol $1.25 \mathrm{mg}$ and dexamethasone $4 \mathrm{mg}$ in the treatment are equally effective and that each reduces the risk of PONV by $25 \%$.[11]

In the 2014 guideline, different from 2007, supportive $\mathrm{O}_{2}$ therapy and minimization of neostigmine use are not included in the strategies to reduce baseline risks. In addition to postoperative opioids, the minimization of intraoperative opioids was also added.[8] After postoperative nausea and vomiting risk assessment, prophylaxis algorithm can be performed (Fig. 1).

\section{General Strategies to Prevent Postoperative Nausea- vomiting}

1. Determine the PONV risk of the patient (low, medium, high)

2. Plan an antiemetic with the purpose of prophylaxis 
(e.g., Put a scopolamine patch two hours before min induction)

3. If PONV develops, calculate the possible problems (e.g., Opening of a wound, increase in the intracranial pressure, aspiration due to jaw braces)

4. The anesthesia technique should be modified (e.g., TIVA instead of sevoflurane anesthesia and regional anesthesia instead of general anesthesia)

5. Postoperative pain control (multimodal analgesia) (e.g., Acetaminophen, local anesthetic application, regional anesthesia/analgesia, wound site infiltration)

6. Antiemetic planning for the rescue purposes Choose a different group antiemetic from the group which was planned for prophylaxis

(e.g., Ondansetron in prophylaxis, prochlorperazine, droperidol in saving)

7. Optimal hydration should be provided

(There is no difference between fluid types)

Approach Strategies according to Risk Groups

\section{A. Approach for the adult patient with high risk}

Multimodal approach (Apfel PONV risk score 4): Triple approach

1. Anesthesia technique: Regional anesthesia if possible; if general anesthesia is necessary, then, TIVA as a choice

2. Antiemetics: From different groups

Scopolamine patch: two hours before minimum induction

Dexamethasone $4 \mathrm{mg}$ iv before induction

Ondansetron $4 \mathrm{mg}$ iv at the end of the surgery

3. Postoperative Pain Control: Acetaminophen, regional blocks, wound site infiltration

\section{B. Approach for the adult patient with medium risk}

(Apfel PONV risk score 2-3): Dual approach

1. Anesthesia technique: If possible regional, TIVA if general anesthesia is necessary

2. Antiemetics:

Dexamethasone $4 \mathrm{mg}$ iv before induction or

Ondansetron $4 \mathrm{mg}$ iv at the end of the surgery

\section{Approach for pediatric patients with high risk}

Multimodal approach (Eberhart PONV risk score 3-4):

1. Anesthesia technique: If possible regional anesthesia+ sedation,

TIVA if general anesthesia is necessary (if there is a very high risk)

2. Antiemetics:

Dexamethasone $0.25 \mathrm{mg} / \mathrm{kg}$ iv, $\max 4 \mathrm{mg}$

Ondansetron $0.1 \mathrm{mg} / \mathrm{kg}$ iv, $\max 4 \mathrm{mg}$
3. Postoperative Pain Control:

Acetaminophen $15 \mathrm{mg} / \mathrm{kg}$ iv, $15-30 \mathrm{mg}$ rectal, max $750 \mathrm{mg}$

Dexmedetomidine infusion $0.3 \mathrm{mg} / \mathrm{kg}$ iv 10 minutes Regional blocks, wound site infiltration

D. Approach for pediatric patients with medium risk Multimodal approach (Eberhart POK risk score 2):

1. Anesthesia technique: If possible regional anesthesia+sedation

2. Antiemetics:

Dexamethasone $0.25 \mathrm{mg} / \mathrm{kg}$ iv, $\max 4 \mathrm{mg}$

Ondansetron $0.1 \mathrm{mg} / \mathrm{kg}$ iv, $\max 4 \mathrm{mg}$

3. Postoperative Pain Control:

Acetaminophen $15 \mathrm{mg} / \mathrm{kg}$ iv, $15-30 \mathrm{mg}$ rectal, max $750 \mathrm{mg}$ Dexmedetomidine infusion $0.3 \mathrm{mg} / \mathrm{kg}$ iv 10 minutes,

Regional blocks, wound site infiltration

\section{E. Approach for adults \& children with low risk:}

Basically in the approach to a low risk patient, antiemetic is not required unless PONV occurs.

It can be applied in some specific surgeries (esophagus surgery, surgeries ended with dental braces)

In a study of hydration and PONV, 100 pediatric strabismus patients were selected. The children were randomized into two groups as Group I ( $10 \mathrm{ml} / \mathrm{kg} \mathrm{RL}$ iv) and Group II (30 ml/kg RL iv). The incidence of PONV (22\%) was lower in the high hydration group than in the low hydration group (54\%). However, when the literature was reviewed, the superiority between fluid types was not shown.

\section{Pharmacological Treatment in PONV Prophylaxis}

Studies have shown that very different medication groups can be used for PONV prophylaxis. The optimal dosages and times of use were clearly indicated. Brief information about the primary medication is as follows:

\section{a. 5-HT3 Receptor Antagonists}

Ondansetron: The gold standard use in the literature is $4 \mathrm{mg}$ intravenously. Studies show that $8 \mathrm{mg}$ of oral ondansetron has a similar effect. Its effect on vomiting is greater than its the effects on nausea. It does not have a sedative effect. The suggested optimal time of use is the end of the surgery. Its main side effects are headache, increased liver enzymes and constipation.

Palonosetron: Palonosetron is the latest serotonin receptor, antagonist. Its half-life is long (about 40 hours). It does not affect the QT interval. It is administered when the surgery is about to end. The suggested dosage for adults is $0.075 \mathrm{mg}$ and $2.5 \mathrm{mcg}$ intravenous for children. 


\section{b. NK-1 Receptor Antagonists}

Aprepitant: There are $80 \mathrm{mg}$ and $40 \mathrm{mg}$ oral dosages. Studies have shown that $80 \mathrm{mg}$ is the ideal dosage.[12] Its half-life is about 40 hours. In a study, it was shown to be superior to ondansetron $4 \mathrm{mg}$ concerning vomiting for 48 hours.[13] In general, it is used for nauseavomiting after cancer cases.

Fosaprepitant: It is the parenteral form.

Rolapitant: It is the new long-acting NK-1 antagonist. Its effect time is about 72-120 hours. Its oral form is $90 \mathrm{mg}$ tablets and can be found in the USA since 2015. Its emulsion form is $166.5 \mathrm{mg}$ and can be found in the USA since 2017. Due to its long-acting effect, it is ideal for ambulatory surgery.

\section{c. Corticosteroids}

Dexamethasone: It has a similar effect with ondansetron $4 \mathrm{mg}$ and droperidol $1.25 \mathrm{mg}$ in prophylaxis.[11] One of their superior characteristics is that they reduce opioid consumption due to having postoperative analgesic effects. There have been ongoing discussions about corticosteroids. One of these discussions is about whether a single dose increases wound infection or not.[14,15] What is certain is that it increases blood sugar for about 6-12 hours, even with the use of non-diabetics. In this respect, the property should be considered when using it. It is also troublesome in pediatric oncology patients because it may lead to tumor lysis syndrome, as well as interact with blood marrow cells.

\section{d. Butyrophenones}

Droperidol: $0.625-1.25 \mathrm{mg}$ dosages are used at the end of surgery. However, according to FDA, it is in the black box list since it extends the QT and can never be the first choice in antiemetics treatment.

Haloperidol: It is used in low dosages $(0.25-2 \mathrm{mg})$ intramuscularly or intravenously. Its primary side effects are prolonged QT and extrapyramidal symptoms. There is no FDA approval for antiemetic and intravenous use. It can be used at the beginning or the end of surgery because there is no difference in its effect.

\section{e. Antihistamines}

Dimenhydrinate/Diphenhydramine: They are as effective as dexamethasone and droperidol. The adult dosage is $1 \mathrm{mg} / \mathrm{kg}$ and the child dosage is $0.5 \mathrm{mg} / \mathrm{kg}$ maximum $25 \mathrm{mg}$ intravenously. Dimenhydrinate is used in oral, im and rectal form. One of the uncertainties about this group of drugs is the dose-response and the lack of optimal administration time. In this group of medication, one of the uncertainties is the dosage reaction and optimal time of use. Their primary side effects are sedation, mouth dryness, dizzi- ness, urinary retention and agitation caused by urinary retention.

\section{f. Propofol}

Propofol is one of the most frequently used medications in the daily practice of anesthesia. The plasma concentration differs depending on the purpose of use. The plasma concentration required for general anesthesia is about $3-6 \mathrm{mcg} / \mathrm{mL}$ and $1-3 \mathrm{mcg} / \mathrm{mL}$ for sedation, whereas it is $343 \mathrm{ng} / \mathrm{mL}$ for the emergence of antiemetic effect. In a study, it has been shown that when propofol is used in induction and maintenance, it reduces PONV by $25 \%$ in particular in the first six hours.[11] In a systematic review in which propofol was compared with inhalation anesthetics (sevoflurane, desflurane, isoflurane), it was shown that it reduces nausea-vomiting after discharge.[16] What is more, it has been shown that when $20 \mathrm{mg}$ propofol, which is a very low dosage in daily practice, is used as an additional antiemetic, it is as effective as $4 \mathrm{mg}$ of ondansetron.[17]

\section{g. Metoclopramide}

It is a weak antiemetic and its place in PONV prophylaxis should be discussed. Although it is effective in large dosages, these dosages $(25-50 \mathrm{mg}$ ) cause side effects, such as hypotension, tachycardia and extrapyramidal symptoms. It is not used in children under the age of 1 and it takes the last place in children's antiemetics preferences $(0.1 \mathrm{mg} / \mathrm{kg}$ iv, $\max 10 \mathrm{mg})$.

\section{Combination Prophylaxis}

In PONV prophylaxis, combination treatments are superior to a single treatment. When the literature is reviewed, the most common drug in combinations is ondansetron. In adults, the maximum medication dosages to be used in combinations are ondansetron 4 $\mathrm{mg}$, dexamethasone $8 \mathrm{mg}$, droperidol $1 \mathrm{mg}$, haloperidol $1.5 \mathrm{mg}$ and propofol $0.5 \mathrm{mg} / \mathrm{kg}$. Since there is no need to use the medication in large dosages in combination treatments, no side effects have been observed.

If the combination examples in the literature are analyzed, these consist of droperidol+ dexamethasone,[11] ondansetron+dexamethasone, ondansetron+droperidol+dexamethasone,[18] ondansetron+casopitant/ transdermal scopolamine.[19]

\section{PONV Prophylaxis Approach for Pediatric Patients}

The medication used for prophylaxis in pediatric patients is similar as well (dexamethasone, dimenhydrinate, dolasetrone, droperidol, granisetrone, ondansetron, tropisetrone). When the combination preferences are reviewed in the literature, it is seen 
that drugs, such as ondansetron+dexamethasone and ondansetron+droperidol, tropisetrone+dexamethasone, are preferred. Ondansetron is seen as the first choice in pediatric patients as well as adults. However, there are limitations to the use of ondansetron in children. Ondansetron's use in children below the age of four months should be monitored. Due to the insufficient development of Sit P450 enzymes, while 0.15 $\mathrm{mg} / \mathrm{kg}$ dosage is used in older children, $0.1 \mathrm{mg} / \mathrm{kg}$ dosage is suitable for use in children below the age of six months. There are advantages and disadvantages of combinations made with the combination of a large number of drugs. A study was performed on the evaluation of postoperative 24 hours of vomiting in children aged 3-16 years. The patients were separated into two groups. The combination used in Group 1 was determined as dexamethasone+ondansetron+placebo (153 patients and the combination for Group 2 was determined as dexamethasone+ondansetron+droperidol (162 patients). A significant difference was not found between the two groups in terms of postoperative vomiting incidence ( $28 \%$ vs. $22 \%)$. Concerning side effects, while numbness was seen in 10 patients with droperidol, it was only seen in two patients in the first group.[18]

\section{Medication without Effect on PONV Prophylaxis}

They are the use of nicotine patches for non-smokers, intraoperative $\mathrm{O}_{2}$ support, music therapy, cannabinoid (nabilone, tetrahydrocannabinol), isopropyl alcohol inhalation, intraoperative gastric decompression, PPI (esomeprazole) and ginger root application.

\section{Conclusion}

Since postoperative nausea and vomiting is a challenging process for patients and their relatives, preoperative risks and treatment strategies should be well determined and precautions should be taken with algorithms.

\section{Peer-review: Externally peer-reviewed.}

Conflict of Interest: Autors declare that there is no conflict of interest.

Financial Support: The authors received no funding for this study.

\section{References}

1. Macario A, Weinger M, Carney S, Kim A. Which clinical anesthesia outcomes are important to avoid? The perspective of patients. Anesth Analg 1999;89(3):652-8.
2. Gan T, Sloan F, Dear Gde L, El-Moalem HE, Lubarsky DA. How much are patients willing to pay to avoid postoperative nausea and vomiting?. Anesth Analg 2001;92(2):393-400.

3. Diez L. Assessing the willingness of parents to pay for reducing postoperative emesis in children. Pharmacoeconomics 1998;13(5 Pt 2):589-95.

4. Carroll NV, Miederhoff PA, Cox FM, Hirsch JD. Costs incurred by outpatient surgical centers in managing postoperative nausea and vomiting. J Clin Anesth 1994;6(5):364-9.

5. Apfel CC, Läärä E, Koivuranta M, Greim CA, Roewer N. A simplified risk score for predicting postoperative nausea and vomiting: conclusions from crossvalidations between two centers. Anesthesiology 1999;91(3):693-700.

6. Gan TJ, Meyer T, Apfel CC, Chung F, Davis PJ, Eubanks S, et al. Consensus guidelines for managing postoperative nausea and vomiting. Anesth Analg 2003;97(1):62-71.

7. Gan TJ, Meyer TA, Apfel CC, Chung F, Davis PJ, Habib AS, et al. Society for Ambulatory Anesthesia guidelines for the management of postoperative nausea and vomiting. Anesth Analg 2007;105(6):1615-28.

8. Gan TJ, Diemunsch P, Habib AS, Kovac A, Kranke P, Meyer TA, et al. Consensus guidelines for the management of postoperative nausea and vomiting. Anesth Analg 2014;118(1):85-113.

9. Eberhart LH, Geldner G, Kranke P, Morin AM, Schäuffelen A, Treiber H, et al. The development and validation of a risk score to predict the probability of postoperative vomiting in pediatric patients. Anesth Analg 2004;99(6):1630-7.

10. Apfel CC, Philip BK, Cakmakkaya OS, Shilling A, Shi YY, Leslie JB, et alA. Who is at risk for postdischarge nausea and vomiting after ambulatory surgery? Anesthesiology 2012;117(3):475-86.

11. Apfel CC, Korttila K, Abdalla M, Kerger H, Turan A, Vedder I, et al. A factorial trial of six interventions for the prevention of postoperative nausea and vomiting. N Engl J Med 2004;350(24):2441-51.

12. Singh PM, Borle A, Rewari V, Makkar JK, Trikha A, Sinha AC, et al. Aprepitant for postoperative nausea and vomiting: a systematic review and meta-analysis. Postgrad Med J 2016;92(1084):87-98.

13. Gan TJ, Apfel CC, Kovac A, Philip BK, Singla N, Minkowitz $\mathrm{H}$, et al. A randomized, double-blind comparison of the NK1 antagonist, aprepitant, versus ondansetron for the prevention of postoperative nausea and vomiting. Anesth Analg 2007;104(5):1082-9.

14. Percival VG, Riddell J, Corcoran TB. Single dose dexamethasone for postoperative nausea and vomiting--a 
matched case-control study of postoperative infection risk. Anaesth Intensive Care 2010;38(4):661-6.

15. De Oliveira GS Jr, Almeida MD, Benzon HT, McCarthy RJ. Perioperative single dose systemic dexamethasone for postoperative pain: a meta-analysis of randomized controlled trials. Anesthesiology 2011;115(3):575-88.

16. Gupta A, Stierer T, Zuckerman R, Sakima N, Parker $\mathrm{SD}$, Fleisher LA. Comparison of recovery profile after ambulatory anesthesia with propofol, isoflurane, sevoflurane and desflurane: a systematic review. Anesth Analg 2004;98(3):632-41.

17. Gan TJ, Ginsberg B, Glass PS, Fortney J, Jhaveri R, Perno R. Opioid-sparing effects of a low-dose infusion of naloxone in patient-administered morphine sulfate. Anesthesiology 1997;87(5):1075-81.

18. Bourdaud N, François C, Jacqmarcq O, Guye ML, Jean J, Studer C, et al. Addition of droperidol to prophylactic ondansetron and dexamethasone in children at high risk for postoperative vomiting. A randomized, controlled, double-blind study. Br J Anaesth 2017;118(6):918-23.

19. Altorjay A, Melson T, Chinachoit T, Kett A, Aqua K, Levin J, et al. Casopitant and ondansetron for postoperative nausea and vomiting prevention in women at high risk for emesis: a phase 3 study. Arch Surg 2011;146(2):201-6. 